\title{
Strategi Pemasaran Hotel Pasca Bencana Gempa Bumi Di Hotel Kota Mataram Dan Daerah Istimewa Yogyakarta
}

\author{
Muhammad Ihdal Karomi ${ }^{1}$, Firman Koma Febdilan ${ }^{2}$, Yoyok Antoni ${ }^{3}$, AA. Ngurah Sedana \\ Putra $^{4}$ Ayu Gardenia Lantang ${ }^{5}$ \\ Program Studi Devisi Kamar, Politeknik Pariwisata Lombok, Indonesia \\ email: ihdal.karomi@ppl.ac.id
}

\begin{abstract}
Abstrak. Tujuan penelitian ini antara lain adalah untuk mengetahui strategi pemasaran internal dan eksternal beberapa hotel di kota Mataram dan beberapa hotel di Yogyakarta pasca bencana gempa bumi. Penelitian ini menggunakan metode penelitian kualitatif melalui pendekatan deskriptif analisis Penelitian ini berlokasi di beberapa Hotel di Kota Mataram dan beberapa Hotel di Yogyakarta karena di dasarkan pada beberapa pertimbangan: dua lokasi penelitian ini pernah mengalami bencana yang sama (gempa bumi) dan merupakan daerah wisata yang menjadi kunjungan favorit wisatawan domestik maupun mancanegara. Strategi pemasaran internal pasca bencana gempa bumi oleh hotel di Kota Mataram dan Yogyakarta yang berfokus pada karyawan dan strategi pemasaran eksternal dengan fokus tamu atau pelanggan menggunakan dan melibatkan semua sumber daya yang dimiliki. Strategi penentuan harga, hotel yang ada di Kota Mataram dan Yogyakarta. Hal ini dilakukan untuk meningkatkan tingkat okupansi. Dari segi strategi promosi hotel, dilakukan promosi bisnis dan promosi tanggungjawab sosial. Melakukan promosi lewat OTA, media sosial, instansi pemerintah dan swasta melalui kegiatan-kegiatan yang dapat meningkatkan okupansi hotel.
\end{abstract}

Kata Kunci : Strategi, Pemasaran, Hotel

Abstract. The purpose of this research is to find out the internal and external marketing strategies of several hotels in the city of Mataram and several hotels in Yogyakarta in the aftermath of the earthquake. This study uses a qualitative research method through a descriptive analysis approach. This research is located in several Hotels in the City of Mataram and several Hotels in Yogyakarta because it is based on several considerations: the two locations of this study have experienced the same disaster (earthquake) and is a tourist area that becomes favorite visit of domestic and foreign tourists. Post-earthquake internal marketing strategies by hotels in Mataram and Yogyakarta City that focus on employees and external marketing strategies with a focus on guests or customers using and involving all available resources. Pricing strategies, hotels in Mataram and Yogyakarta. This is done to increase the level of occupancy. In terms of hotel promotion strategies, business promotion and social responsibility promotion are carried out. Promoting through OTA, social media, government agencies and the private sector through activities that can increase hotel occupancy.

Keywords: Strategy, Marketing, Hotels

\section{PENDAHULUAN}

Sektor pariwisata di Indoenesia dewasa ini mengalami pertumbuhan yang sangat pesat, di mana berbagai destinasi wisatanya selalu ramai dikunjungi oleh wisatawan mancanegara maupun wisatawan domestik. Tercatat pada periode tahun 2011 sampai tahun 2017, berdasarkan data dari World Travel and
Tourism Council (WTTC); melaporkan bahwa Top-30 Travel and Tourism Countries Power Ranking yang didasarkan pada pertumbuhan absolut untuk empat indikator perjalanan dan pariwisata utama menunjukkan Indonesia berada pada nomor 9 (sembilan) sebagai negara dengan pertumbuhan pariwisata tercepat di dunia. 
Salah satu daerah di Indonesia yang memiliki potensi sektor pariwisata untuk dikembangkan adalah Provinsi Nusa Tenggara Barat (NTB). Sektor pariwisata merupakan salah satu sektor andalan pemerintah Nusa Tenggara Barat untuk menghasilkan devisa (Isnaini, 2016:3). Menurut data Badan Pusat Statistik (ntb.bps.go.id), Provinsi NTB berhasil menerima kunjungan lebih dari 3,5 juta wisatawan pada tahun 2017, yang terdiri dari 2.078.654 wisatawan nusantara dan 1.430.249 wisatawan mancanegara, meningkat $13 \%$ dari tahun 2016 yang pada saat itu menerima kunjungan 3.094.437 wisatawan.

Angka kunjungan wisatawan yang meningkat ini pun kemudian berbanding lurus dengan tingkat pertumbuhan bisnis hotel di Provinsi NTB. Mekanisme pasar bekerja, sebagaimana jumlah jumlah wisatawan yang datang semakin banyak, maka permintaan kamar juga pastinya akan meningkat (Wijaya dan Santoso, 2018:43). Sebagai catatan pada tahun 2017 saja, jumlah hotel/akomodasi yang sudah eksis di Provinsi NTB sebanyak 889 unit; dengan rincian hotel bintang sebanyak 75 unit dan hotel non bintang 814 unit. Kemudian dari jumlah hotel tersebut, hotel dengan klasifikasi berbintang menyediakan kamar sebanyak 4.525 unit dengan jumlah tempat tidur yang tersedia sebanyak 6.721 unit. Sadangkan hotel dengan klasifikasi non bintang (melati, penginapan remaja, pondok wisata, dan jasa akomodasi lainnya) menyediakan kamar sebanyak 8.892 unit dengan jumlah tempat tidur 12.460 unit. Berdasarkan grafik, setiap tahun jumlah hotel/akomodasi di Provinsi NTB terus bertambah. Pada tahun 2010, jumlah hotel hanya sebanyak 379 unit dan selama dalam rentang waktu 6 (enam) tahun, terus mengalami peningkatan

\section{Gambar 1. Grafik Perkembangan Jumlah Hotel/Akomodasi di NTB}

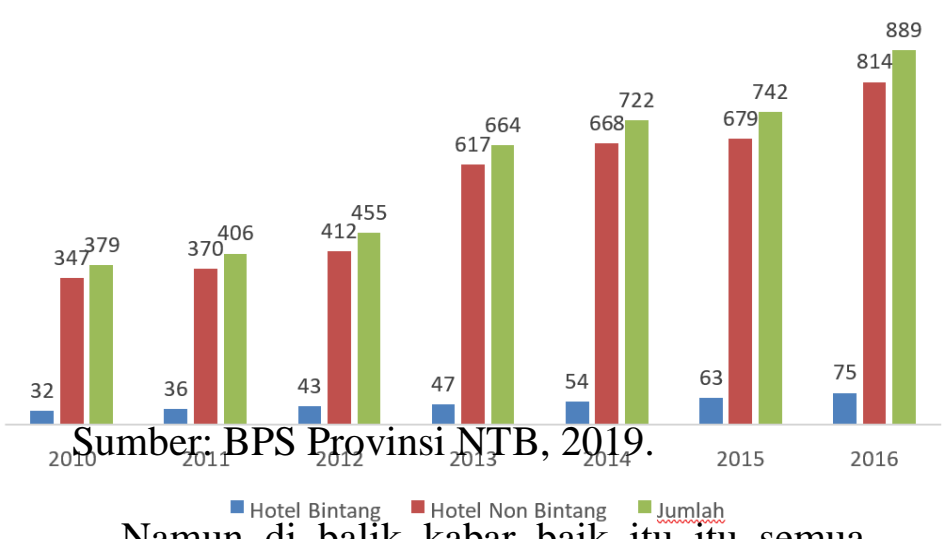

Namun di balik kabar baik itu itu semua, ternyata industri ini sangat rentan akan berbagai isu; salah satunya adalah bencana alam. Bencana alam dapat terjadi di mana saja, kapan saja, dan kepada siapa saja. Terjadi sampai dengan frekuensi bencana itu pun sampai saat ini sulit diprediksi, bisa hanya sekali dalam ratusan tahun, setahun sekali atau hanya pada saat-saat tertentu. Sangat sulit unluk memprediksi di mana bencana alam akan terjadi, untuk berapa lama, dan berapa kuat serta besar dampaknya (Daniels and Daniels, 2003).

Rentetan musibah bencana gempa bumi yang mengguncang provinsi NTB pada periode waktu Juli-Agustus 2018 tahun lalu merupakan fase-fase sulit bagi pelaku bisnis hotel. Musibah tersebut mengakibatkan banyak sekali kerugian, baik berupa kerugian fisik (infrasrtuktur), psikologis masyarakat (trauma), sampai pada puncaknya yaitu menurunnya aktifitas ekonomi.

Kondisi serupa juga pernah dialami daerah lain, salah satunya adalah Yogyakarta. Tepatnya pada saat terjadi bencana gempa bumi di tahun 2006 yang membawa dampak psikologis berupa rasa trauma yang menghinggapi masyarakat dan rusaknya infrastruktur dan bangunan publik yang sangat signifikan, termasuk bangunan hotel dan akomodasi lainnya sehingga menyebabkan terganggunya aktifitas ekonomi. Gempa dengan besaran magnitude 5,9 SR kala itu meluluhlantakkan Yogyakarta bagian selatan 
Jurnal Ilmiah Mandala Education

http://ejournal.mandalanursa.org/index.php/JIME/index

terakreditasi Peringkat 4 (No. SK: 36/E/KPT/2019)

dan menyebabkan 4.674 orang meninggal dunia serta 19.897 orang luka-luka. Tidak hanya itu, sebanyak 96.730 rumah rata tanah dan 117.075 rumah rusak berat. Pemerintah Indonesia memperkirakan kerugian yang diakibatkan oleh gempa selama 52 detik itu mencapai Rp29,1 triliun. (https://tirto.id/bkWg, diakses Oktober 2019)

Untuk mendapatkan gambaran yang utuh mengenai strategi pemasaran hotel, maka fokus penelitian program studi tidak hanya sebatas hotel yang ada di kota Mataram, tapi juga hotel yang ada di Yogyakarta, dengan mempertimbangkan Yogyakarta dahulunya juga pernah mengalami bencana yang serupa dengan yang ada di kota Mataram dan hotel di daerah tersebut kami nilai berhasil di dalam mengelola kembali bisnis perhotelan melalui strategi pemasaran yang tepat.

Oleh karena itu, dianggap perlu mengangkat isu ini ke dalam sebuah penelitian kelompok Program Studi Divisi Kamar, dengan judul Strategi Pemasaran Hotel Pasca Bencana Gempa Bumi di Hotel Kota Mataram dan Yogyakarta.

\section{TINJAUAN PUSTAKA}

Pemasaran umumnya dipandang sebagai tugas untuk menciptakan, memperkenalkan, dan menyerahkan barang atau jasa kepada konsumen dan perusahaan lain. Menurut Kotler (2005:17) "Marketing mix is the set of marketing tools that the firm uses to pursue its marketing objective in the target market.", pemasaran diartikan seperangkat alat pemasaran yang digunakan perusahaan untuk terus-menerus mencapai tujuan pemasarannya di pasar sasaran. Menurut Zeithaml dan Bitner, dikutip oleh Ratih Hurriyati (2005:28) "Marketing mix defined as the elements an organization appear as core decision variables in any marketing text or marketing plan." Yaitu elemen-elemen organisasi perusahaan yang dapat dikontrol oleh perusahaan dalam melakukan komunikasi dengan konsumen dan akan dipakai untuk memuaskan konsumen, atau bisa diartikan bahwa bauran pemasaran adalah
Vol. 6. No. 2. Oktober 2020 p-ISSN: 2442-9511 e-ISSN: 2656-5862 seluruh komponen pemasaran yang dapat digunakan dan dikontrol oleh perusahaan untuk memuaskan pelanggan dan mencapai tujuan perusahaan. Menurut Sofjan Assauri (2013:12), Manajemen Pemasaran adalah kegiatan menganalisis, merencanakan, melaksanakan dan mengendalikan program-program yang disusun dalam pembentukan, pembangunan, dan pemeliharaan keuntungan dari pertukaran/ transaksi melalui sasaran pasar dengan harapan untuk mencapai tujuan organisasi (perusahaan) dalam jangka panjang. Menurut Suparyanto \& Rosad (2015:1), manajemen pemasaran adalah proses menganalisis, merencanakan, mengatur, dan mengelola program- program yang mencakup pengkonsepan, penetapan harga, promosi dan distribusi dari produk, jasa dan gagasan yang dirancang utnuk menciptakan dan memelihara pertukarn yang menguntungkan dengan pasar sasaran untuk mencapai tujuan perusahaan.

\section{METODE PENELITIAN}

Penelitian ini menggunakan metode penelitian kualitatif melalui pendekatan deskriptif analisis, sebagai prosedur penelitian yang menghasilkan data deskriptif berupa katakata tertulis atau lisan dari perilaku yang dapat diamati. Tim peneliti turun langsung ke lapangan dan mengobservasi, mengamati, dan langsung berinteraksi dengan pihak-pihak yang mendukung terjawabnya rumusan masalah dari penelitian ini.

Penelitian ini berlokasi di Kota Mataram sebanyak 7 (tujuh) hotel yakni Hotel Golden Palace, Hotel Santika, Hotel Lombok Astoria, Hotel Lombok Garden, Hotel Puri Indah, Hotel Lombok Raya dan Svarga Resort. Untuk di Yogyakarta yakni Hotel Santika Premier, The Phoenix Hotel dan Prima Inn. Pemilihan hotel di Yogyakarta di dasarkan pada beberapa pertimbangan: dua lokasi penelitian ini pernah mengalami bencana yang sama (gempa bumi) dan merupakan daerah wisata yang menjadi kunjungan favorit wisatawan domestik maupun mancanegara. Selain itu, alasan kami menjadikan Hotel di daerah Yogyakarta sebagai 
rujukan yang tepat adalah karena daerah tersebut mampu membangun kembali atau bangkit dari musibah yang mereka alami, sehingga tim peneliti ingin mengetahui bagaimana cara atau strategi hotel di Yogyakarta mensiasati kondisi pasca gempa bumi untuk meningkatkan hunian hotel atau okupansi mereka sampai saat ini.Teknik pengumpulan data dalam penelitian ini adalah wawancara, observasi serta dokumentasi.

Analisis data dalam penelitian ini menggunakan analisis data kualitatif, jadi dalam analisis data selama di lapangan peneliti menggunakan model analisis data interaktif Miles dan Huberman (Miles, Huberman dan Saldana, 2014:14). Adapun tahap-tahap analisis menjadi tiga langkah, yaitu: Reduksi data, Penyajian Data dan Menarik Kesimpulan/Verifikasi.

\section{HASIL DAN PEMBAHASAN}

Kondisi Industri Pariwisata, khususnya bisnis perhotelan di Kota Mataram pasca bencana gempa bumi 2018 dalam kondisi membaik, walaupun sebenarnya belum pulih seutuhnya. Seperti yang ditampilkan dalam tabel persentase tingkat hunian hotel di Kota Mataram tahun 2018 dan 2019 berikut ini.
Tabel 1. Tabel Persentase Tingkat Hunian Hotel di Kota Mataram Tahun 2018 dan 2019

\begin{tabular}{|c|c|c|c|c|c|c|c|c|c|c|c|c|c|}
\hline \multirow{2}{*}{ NAME } & \multicolumn{12}{|c|}{ MONTH TO DATE OCCUPANCY PERCENT 2018} & \multirow{2}{*}{$\begin{array}{l}\text { YTD } \\
\text { OCC\% }\end{array}$} \\
\hline & $\sqrt{\operatorname{ann}-18}$ & Feb-18 & Mar-18 & Apr-18 & May-18 & Jun-18 & $\mid \mathrm{Ju}-18$ & Aug-18 & Sep-18 & $0 c t-18$ & Nov-18 & Dec:-18 & \\
\hline Golden Palace Hotel & 38.07 & 57.51 & 76.09 & 82.98 & 69.09 & 48.17 & 80.88 & 11.40 & 11.82 & 41.05 & 52.47 & 51.41 & 53.99 \\
\hline Grand legi Hotel & 20.23 & 39.57 & 43.92 & 52.43 & 42.37 & 21.14 & 46.43 & 62.96 & 47.79 & 33.68 & 41.28 & 39.59 & 40.97 \\
\hline Lombok Astoria & 53.48 & 62.7 & 75.55 & 66.50 & 62.06 & \begin{tabular}{|l|l|}
45.62 \\
\end{tabular} & 72.14 & 28.39 & 26.48 & \begin{tabular}{|l|}
47.97 \\
\end{tabular} & \begin{tabular}{|l|}
47.83 \\
\end{tabular} & 51.91 & 53.38 \\
\hline Lombok Plaza Hotel & 73.65 & 70.42 & 71.56 & 70.68 & 68.45 & 49.39 & 64.86 & 28.12 & 36.96 & 48.49 & 51.61 & 48.52 & 56.86 \\
\hline Lombok Raya Hotel & 18.6 & 31.76 & 36.73 & 54.24 & 41.59 & 15.81 & 48.20 & 6.25 & 29.56 & 41.09 & 41.15 & 40.09 & 33.80 \\
\hline Santika Hotel & 64.65 & 78.4 & 78.08 & 78.16 & 69.60 & 42.66 & 81.30 & 27.22 & 47,05 & 66.75 & 70.51 & 67.16 & 64.23 \\
\hline Aston Inn & 70.27 & 74.48 & 84.86 & 81.21 & 77.47 & 64.41 & 82.98 & 45.91 & 28.10 & 44.09 & 52.79 & 58.44 & 63.74 \\
\hline CTY occ\% & 48.42 & \begin{tabular}{|l|}
59.26 \\
\end{tabular} & 666.68 & 69.46 & 61.52 & 41.03 & 68.11 & 30.04 & 32.54 & 46.16 & 51.09 & 51.02 & 52.42 \\
\hline
\end{tabular}

\begin{tabular}{|c|c|c|c|c|c|c|c|c|c|c|c|c|c|}
\hline \multirow{2}{*}{ NAME } & \multicolumn{12}{|c|}{ MONTH TO DATE OCCUPANCY PERCENT 2019} & YTD \\
\hline & Jan-19 & Feb-19 & Mar-19 & Apr 19 & Mar-19 & Jun-19 & Jul-19 & Aug-19 & $\operatorname{Sep-11}$ & $0 c t-1$ & Nov-19 & Dec-19 & OCC\% \\
\hline Golden Palace Hotel & 26.16 & 33.69 & 52.52 & 47.82 & 34,02 & 43.11 & 57.26 & 50.44 & 64.23 & 73.2 & 66.91 & & 49.95 \\
\hline Grand Legi Hotel & 31.24 & 22.96 & 25.64 & 35.64 & 30.79 & 31.23 & 28.55 & 30.65 & 48.36 & 55.55 & 41.49 & & 34.79 \\
\hline Lombok Astoria & 36.39 & 37.04 & 44.39 & 47.93 & 39.38 & 41.06 & 57.75 & 56.67 & 54,31 & 67.80 & 68.54 & & 50.20 \\
\hline Lombok Plaza Hotel & 42.69 & 49.57 & 46.79 & 45.53 & 47.38 & 40.69 & 49.28 & 41.91 & 44.49 & 53.05 & 48.11 & & 46.31 \\
\hline Lombok Raya Hotel & 17.67 & 33.63 & 25.89 & 26.40 & 33.66 & 29.57 & 41.62 & 40.79 & 54,13 & 56.56 & 54.14 & & 36.84 \\
\hline Santika Hotel & 58.48 & 63.01 & 61.84 & 51.14 & 52.92 & 40.98 & 56.60 & 53.40 & 61.00 & 70.29 & 65.66 & & 57.75 \\
\hline Aston lnn & 47.39 & 50.77 & 55.33 & 44.82 & 44,47 & 47.38 & 60.50 & 67.27 & 73.54 & 79.01 & 80.31 & & 59.21 \\
\hline aTY occ\% & 37.15 & 41.52 & 44.63 & 42.75 & 40.37 & 39.15 & 50.22 & 48.73 & 57.15 & 65.07 & 60.74 & & 47.86 \\
\hline
\end{tabular}

Sumber: Sales and Marketing Golden Palace Hotel, 2019.

Dari tabel di atas digambarkan bagaimana terjadi peningkatan occupancy di beberapa hotel di Kota Mataram pada bulan Oktober tahun 2018, tepat 3 (tiga) bulan pasca gempa bumi di bulan Agustus 2018. Peningkatan occupancy pun terus terjadi sampai pada akhir Desember 2018 dan berlanjut hingga tahun 2019. Hal ini tentu saja tidak lepas dari upaya manajemen hotel di kota Mataram dalam memasarkan kembali hotelnya, baik melalui strategi pemasaran internal yang berfokus pada karyawan maupun pemasaran eksternal dengan fokus tamu/pelanggan menggunakan dan melibatkan semua sumber daya yang dimiliki.

Kelebihan hotel-hotel yang ada di Yogyakarta setelah pasca gempa melakukan trauma healing dan didukung masyarakat untuk segera bangkit dari musibah yang terjadi. Keterlibatan masyarakat luas juga mempercepat pemulihan pasca gempa yang terjadi. Tahun 2006, peran sosial media tidak begitu masiv dibandingkan dengan saat ini sangat 
membantu dalam pemulihan, bangunanbangunan terdampak tidak dimunculkan atau tidak diupload. Kelebihan di Lombok pasca gempa bumi, masyarakat semakin sadar terutama pelaku atau industri pariwisata terutama industri hotel terhadap keadaan darurat kebencanaan. Pelaksanaan Safety briefing dilakukan secara rutin kepada pengguna hotel.

Kelemahan di Lombok, semakin masivnya media sosial, masyarakat dengan mudahnya mengupload bencana yang terjadi atau dampak dari bencana di media sosial, sehingga memperburuk citra daerah yang tidak aman dan sering terjadi bencana. Kelemahan juga terdapat di Yogyakarta karena hanya memasarkan akomodasi di Yogyakarta secara konvensional.

\section{Pemasaran Internal Hotel Pasca Bencana Gempa Bumi}

Yogyakarta pernah mengalami musibah yang serupa dengan Lombok, tepatnya bencana gempa bumi di tahun 2006. Dampak psikologis berupa rasa trauma yang menghinggapi masyarakat dan bangunan fisik yang rusak juga turut dirasakan. Infrastruktur dan bangunan publik mengalami kerusakan yang signifikan, termasuk bangunan hotel dan akomodasi lainnya. Program pemasaran internal yang dilakukan oleh pihak hotel di Yogyakarta juga sama seperti yang dilakukan di Kota Mataram, yaitu memulihkan mental karyawan melalui kegiatan trauma healing serta melakukan pengecekan fisik bangunan tentang kelayakan dan keamanan bangunan untuk ditempati atau digunakan oleh pihak atau instansi yang berwenang yang berhak memberikan sertifikasi kelayakan bangunan.

Perbedaan yang paling signifikan mengenai strategi pemasaran internal hotel di Kota Mataram dan Yogyakarta adalah terletak pada cara penanganan berita dan konten terkait bencana gempa bumi yang telah terjadi. Faktor yang menurut kami sangat mempengaruhi hal tersebut adalah timeline yang sangat berbeda antara gempa yang terjadi di Yogyakarta pada tahun 2006 dengan apa yang dialami Lombok pada tahun 2018. Kondisi sosial masyarakat di era disruptif teknologi internet saat ini menyebabkan begitu cepatnya informasi menyebar. Masifnya pemberitaan pada saat dan pasca terjadinya gempa di Lombok tahun 2018 silam melalui postingan di media sosial dan aplikasi percakapan dapat kita rasakan dampaknya, bahkan sampai hari ini. Sementara bencana gempa bumi di Yogyakarta pada tahun 2006 lalu, oleh tim peneliti menilai tren penggunaan media sosial dan aplikasi percakapan belum tumbuh pesat seperti saat ini. Seperti yang dilakukan oleh Hotel Santika Premier Yogyakarta dan The Phoenix Hotel Yogyakarta, pemberitaan yang positif hanya dilakukan oleh pihak hotel, yakni melalui bagian hubungan public (public relation) dan bagian marketing komunikasi. Karyawan mereka hanya dihimbau agar tidak bercerita kepada masyarakat ataupun tamu mengenai kondisi tempat kerja mereka yang rusak akibat gempa.

\section{Strategi Pemasaran Eksternal Hotel Pasca Bencana Gempa Bumi di Kota Mataram dan Yogyakarta. \\ Produk}

Berangkat dari pertanyaan tim peneliti kepada pengelola hotel di Kota Mataram dan Yogyakarta, yaitu "Permasalahan apakah yang muncul terkait produk (fisik \& pelayanan) yang ditawarkan Hotel akibat bencana gempa yang terjadi?", keseluruhan dari mereka menjawab terdapat kerusakan fisik dengan skala yang beragam, mulai dari kerusakan ringan, sedang, sampai berat. Baik hotel yang ada di Kota Mataram dan Yogyakarta pasca gempa yang terjadi dengan sesegera mungkin melakukan perbaikan dan peningkatan pelayanan baik pada produk nyata, tidak nyata, perishabel dan non perishable. Melakukan perbaikan dan peningkatan baik secara fisik dan non fisik untuk menarik calon tamu agar menginap di hotel tersebut. Pasca gempa yang terjadi, hotel menggunakan waktu untuk berbenah dan memperbaiki fasilitas yang mengalami kerusakan sehingga pada saat hotel membuka kembali (grand opening), fasilitas sudah dapat 
dinikmati kembali seperti semula, bahkan fasilitas dan pelayanan yang diberikan ada yang terbarukan. Melalui strategi pemasaran yang ditetapkan pascagempa, maka pada tahun 2019 di bulan Juni keuntungan mencapai $9 \%$ dan pada bulan Juli ada peningkatan 3\% mencapai $12 \%$.

\section{Harga (Price)}

Harga (price) adalah suatu sistem manajemen perusahaan yang akan menentukan harga dasar yang tepat bagi produk atau jasa dan harus menentukan strategi yang menyangkut potongan harga, pembayaran ongkos angkut dan berbagai variabel yang bersangkutan (Kotler \& Keller, 2016:47). Pricing strategy di dalam bisnis perhotelan ditetapkan dengan tujuan untuk: Meningkatkan penjualan produk dan jasa hotel, mempertahankan dan meningkatkan market share, menstabilkan tingkat harga/rate produk atau jasa hotel.

Dari hasil wawancara tim peneliti dengan hotel yang ada di Kota Mataram dan Yogyakarta, pertanyaan yang diberikan antara lain "Strategi pemasaran apakah yang dilakukan hotel, dalam hal ini yang berkaitan dengan rate/harga dari produk yang ditawarkan pasca bencana terjadi?

Pricing strategy yang dilakukan Hotel Lombok Raya, untuk harga atau rate yang diterapkan tidak ada perubahan seperti biasa sebelum adanya gempa. Hal yang dilakukan adalah menambah jadwal promosi dengan terjun ke lapangan dalam hal ini mendorong tim sales marketing mereka agar lebih aktif lagi dalam mempromosikan hotel. Berbeda dengan Hotel Lombok Garden yang melakukan penuruan harga kamar sampai dengan 10-15\% dari harga normal. Penurunan harga/rate yang mereka berlakukan tidak mempengaruhi kondisi jumlah karyawan. Hal ini dilakukan oleh pihak manajemen agar tidak memberatkan beban ekonomi karyawan yang sudah terpuruk karena tidak adanya uang service. Penurunan harga yang dilakukan oleh Hotel Lombok Garden diikuti dengan jumlah okupansi yang cukup tinggi, hal ini dikarenakan banyak tamu yang menginap atau tinggal di hotel yang berlantai maksimal 2 (dua) lantai. Tamu merasa lebih aman dan nyaman menginap di hotel yang berlantai hanya maksimal 2 (dua) lantai.

\section{Promosi}

Promosi (promotion) merupakan kegiatan yang dilakukan perusahaan untuk mengkomunikasikan manfaat produk dan sebagai alat untuk mempengaruhi konsumen dalam kegiatan pembelian atau penggunaan jasa sesuai dengan kebutuhan (Lupiyoadi, 2013:92).

Berikut ini akan dijabarkan hasil wawancara tim peneliti dengan hotel yang ada di Kota Mataram dan Yogyakarta, terkait pertanyaan yang diberikan antara lain "Strategi promosi apa sajakah yang dilakukan hotel dalam memasarkan produknya pasca bencana terjadi?".

Hotel yang ada di Kota Mataram dan Yogyakarta memiliki beberapa persamaan dan perbedaan di dalam menerapkan strategi pemasaran pasca bencana yang mereka miliki, dalam hal ini strategi promosi. Persamaan yang pertama adalah kedua hotel di daerah ini samasama memanfaatkan media cetak dan elektronik untuk memrpomosikan produk dan jasa hotel mereka pasca bencana. Pihak manajemen hotel di Kota Mataram dan Yogyakarta memberikan informasi melalui media cetak dan elektronik terkait hal-hal yang sudah mereka lakukan pasca gempa yang terjadi. Promosi yang mereka lakukan terbagi menjadi 2 (dua) segmen; promosi bisnis dan promosi tanggungjawab sosial. Promosi bisnis yang dilakukan adalah dengan mengkomunikasikan upaya yang dilakukan oleh hotel untuk mengembalikan kepercayaan konsumen terhadap bisnis mereka, meliputi: perbaikan bangunan, sarana, prasarana, dan penambahan fasilitas hotel pasca bencana; jaminan mendapatkan pelayanan yang terbaik, jaminan keamanan dan kenyamanan bagi tamu yang akan menggunakan fasilitas yang disediakan oleh hotel; pemberian potongan harga, dan lainlain. Sementara promosi tanggungjawab sosial 
Jurnal Ilmiah Mandala Education

http://ejournal.mandalanursa.org/index.php/JIME/index

terakreditasi Peringkat 4 (No. SK: 36/E/KPT/2019)

yang dilakukan adalah dengan

mengkomunikasikan aktifitas sosial hotel yang terlibat di dalam program trauma healing bagi karyawan dan kegiatan bakti sosial di daerah terdampak bencana.

Persamaan yang kedua adalah dengan ikut terlibat dalam mempromosikan daerah mereka yang terdampak bencana bersama semua pihak yang ada di dalam unsur Pentahelix. Unsur Pentahelix itu adalah Pemerintah; Akademisi; Asosiasi; Komunitas dan Media, yang saling terkait satu sama lain. Dukungan dari pemerintah pusat dan daerah ialah dengan cara menunjuk Kota Mataram dan Yogyakarta sebagai pusat kegiatan meeting. Ini dilakukan dalam rangka menjamin kepercayaan setiap wisatawan yang nantinya akan berkunjung bahwa Kota Mataram dan Yogyakarta itu sudah aman untuk dikunjungi. Dengan dilaksanakannya meeting di daerah yang terdampak bencana tersebut, diharapkan dapat membantu secara finansial hotel-hotel yang terdampak secara fisik dan ekonomi oleh bencana gempa. Dukungan dari asosiasi diberikan melalui dilaksankannya berbagai macam kegiatan baik itu oleh Asita, Astindo, PHRI, INCCA, dan lain-lain; melalui Kegiatan Table Top, Travel Fair, Sales Missions, Fam Trip dan sebagainya; yang menjadikan daerah terdampak bencana sebagai tempat dilaksanakannya kegiatan tersebut. Dukungan dari masyarakat Kota Mataram dan Yogyakarta yang turut bergerak untuk membenahi tempattempat yang terdampak gempa agar wisatawan tidak merasa takut dan terganggu oleh puingpuing bangunan yang roboh akibat gempa yang terjadi. Dukungan dari akademisi adalah dengan melakukan kajian kebencaan di daerah terdampak bencana dalam rangka menyiapkan program mitigasi atau pengelolaan sistem manajemen krisis kepariwisataan di masa yang akan datang.

Perbedaan yang paling fundamental dari strategi promosi pasca bencana gempa yang dilakukan hotel di Kota Mataram dan hotel di Yogyakarta adalah berdasarkan kondisi yang jauh sangat berbeda di tahun 2006 dan tahun
2018. Era saat ini dikenal juga dengan era disruptif teknologi yang menyebabkan begitu cepatnya informasi menyebar. Media sosial, aplikasi percakapan, dan aplikasi Online Travel Agent (OTA) merupakan beberapa tren yang digandrungi wisatawan saat ini. Sebagai contohnya Svarga Resort; sebelum bencana gempa terjadi, $70 \%$ pejualan kamar mereka berasal dari OTA. Sedangkan, pasca gempa pemasaran didukung oleh OTA sekitar $80 \%$, bahkan manajemen hotel mereka juga menyatakan tidak hanya OTA yang mendukung promosi mereka, namun mereka juga yang mendukung promosi OTA. Sementara di Yogyakarta pada tahun 2006 lalu, promosi hotel baik oleh Santika Premier Yogyakarta dan The Phoenix Hotel Yogyakarta pasca gempa dilakukan dengan cara-cara yang konvensional, yaitu melalui website yang mereka kelola sendiri, email, pengiriman program promosi ke instansi-instansi baik pemerintah maupun swasta, dan lain-lain.

\section{KESIMPULAN}

Strategi pemasaran pasca bencana gempa bumi oleh hotel di Kota Mataram dan Yogyakarta dilakukan melalui program srategi pemasaran internal yakni : trauma healing pada karyawan, safety briefing untuk karyawan, upgrade knowledge kepada karyawan tentang kekuatan dan struktur bangunan hotel yang kokoh dan masih aman, menghimbau kepada seluruh karyawan agar tidak mempublikasikan atau mengkomunikasikan hal-hal yang berkaitan dengan kondisi hotel pasca bencana. Mendorong karyawan melakukan pemberitaan yang positif ke media massa maupun media sosial yang mereka miliki, melakukan upaya peningkatan kerjasama dan kesadaran kolektif seluruh karyawan untuk melakukan penyebaran berita maupun konten positif terkait hotel tempat mereka bekerja dengan sekaligus memberikan sanksi apabila terdapat karyawa yang melanggar karena memposting hal-hal yang kurang tepat di aplikasi percakapan maupun media sosial yang mereka miliki. 
Jurnal Ilmiah Mandala Education

http://ejournal.mandalanursa.org/index.php/JIME/index

terakreditasi Peringkat 4 (No. SK: 36/E/KPT/2019)

Strategi pemasaran eksternal pasca gempa bumi oleh hotel di Kota Mataram dan Yogyakarta yang dalam hal ini adalah strategi pemasaran produk adalah dengan dilakukannya perbaikan dan peningkatan produk dan jasa hotel yang terdampak bencana gempa bumi dan melakukan perombakan kamar tamu menuju konsep yang lebih efisien. Dalam hal strategi penentuan harga, hotel yang ada di Kota Mataram dan Yogyakarta, menurunkan harga 5\%-10\% dari harga normal dan terdapat juga penurunan harga sampai $60 \%$. Hal ini dilakukan untuk meningkatkan tingkat okupansi yang turun drastic pasca bencana gempa bumi. Dari segi strategi promosi hotel, dilakukan promosi bisnis dan promosi tanggungjawab sosial. Hotel di Kota Mataram melakukan promosi lewat OTA, media sosial, instansi pemerintah dan swasta melalui kegiatan-kegiatan yang dapat meningkatkan okupansi hotel, sedangkan di Yogyakarta tidak meggunakan OTA dan media sosial karena di era itu (2006) belum dikenal istilah OTA dan media sosial seperti sekarang ini.

\section{DAFTAR PUSTAKA}

Alma, Buchari. (2010) Manajemen Pemasaran dan Pemasaran Jasa. Bandung: Alfabeta

Anisa, Rahma. (2015) “Hubungan Antar Citra yang Berlaku (current image) dengan tingkat hunian kamar Hotel Grand Royal Panghegar", Fakultas Ilmu Komunikasi Universitas Islam Bandung.

Assauri, Sofjan. (2013) Manajemen

Pemasaran. Jakarta: Rajawali Pers.

Bahasa: Alexander Sindoro. Jakarta. Penerbit Prenhallindo

Kotler, Philip. (2012) Marketing Reaserch. Edisi Kedua. Yogyakarta. Penerbit Koputindo

Budi, Sulistino, Ari. (2010) "Pengaruh Kualitas Pelayanan, Fasilitas, dan Lokasi terhadap Keputusan Menginap Tamu Hotel Srondol Indah Semarang”, Fakultas Ekonomi Universitas Dipenogoro Medan.
Vol. 6. No. 2. Oktober 2020 p-ISSN: 2442-9511 e-ISSN: 2656-5862
Haryono. (2015) Dashyatnya Pengelolaan Sumber Daya Manusia Dalam Bisnis Perhotelan. Jakarta: Fakultas Ekonomi Universitas Indonesia.

Hurriyati, Ratih. (2005) Bauran Pemasaran dan Loyalitas Konsumen. Bandung: Alfabeta.

Isnaini, L,M,Y. (2016) Pengembangan Sport Tourism Di NTB. Jurnal Lembaga Pendidikan. Vol 1. No 1.

Kasmir, 2014. Kewirausahaan. Jakarta: PT. RajaGrafindo Persada.

Kelompok Gramedia.

Kotler dan Keller, (2012) Marketing Management Edisi 14, Global Edition.

Kotler, Philip dan Gary Armstrong. (2012) Dasar-Dasar Pemasaran. Jilid 1. Alih

Kotler, Philip.(2005) Manajemen Pemasaran Jilid 1 dan 2. Jakarta: PT Indeks

Meskardo, Sembiring. (2015) Omset Berlipat dari Bisnis Hotel, Tur, dan Travel. Jakarta: Cermelang Publishing.

Pearson Prentice Hall.

Rangkuti, Freddy. (2014) Analisis SWOT: Teknik Membedah Kasus Bisnis. Jakarta: PT Gramedia Pustaka Utama

Sugiarto, Endar. (2009) Hotel Front Office Administraction (Administrasi Kantor Depan Hotel). Jakarta: PT. Gramedia Pustaka Utama,

Sulistiyono, Agus. (2008) Manajemen Penyelenggara Hotel, Cetakan ke 6. Bandung: Alfebeta.

Sumarni, Murti \& John Soeprihanto. (2010) Pengantar Bisnis (Dasar-dasar Ekonomi Perusahaan) Edisi ke 5. Yogyakarta: Liberty Yogyakarta

Sumarsono, Dicky.( 2014). Dahsyatnya Bisnis Hotel Di Indonesia. Jakarta: PT. Gramedia Pustaka Utama.

Suparyanto \& Rosad. (2015) Manajemen Pemasaran. Bogor: IN MEDIA

Tjiptono, Fandi. 2008. Strategi Pemasaran Edisi Ke 3. Yogyakarta: Andi Office.

Wijaya, C,P., Santoso, T,P,B. (2018) Strategi Pemasaran Dalam Meningkatkan Hunian Kamar Pada Hotel Bali Mandira Legian- 
Jurnal Ilmiah Mandala Education

http://ejournal.mandalanursa.org/index.php/JIME/index

Vol. 6. No. 2. Oktober 2020

terakreditasi Peringkat 4 (No. SK: 36/E/KPT/2019)

Bali. Universitas Dahyna Pura. Vol. No 12018. 